\title{
Endoscopic Management of Foreign Body Impaction in the Upper Gastrointestinal Tract in a Tertiary Care Centre of Nepal
}

\author{
Shrestha A, Gurung RB, Sharma P, Shrestha R, Shrestha P
}

Department of Internal Medicine

Dhulikhel Hospital, Kathmandu University Hospital

Kathmandu University School of Medical Sciences

Dhulikhel, Kavre, Nepal.

\section{Corresponding Author}

Ashish Shrestha

Department of Internal Medicine

Dhulikhel Hospital, Kathmandu University Hospital Kathmandu University School of Medical Sciences Dhulikhel, Kavre, Nepal.

E-mail: ashish@kusms.edu.np

\section{Citation}

Shrestha A, Gurung RB, Sharma P, Shrestha R, Shrestha P. Endoscopic Management of Foreign Body Impaction in the Upper Gastrointestinal Tract in a Tertiary Care Centre of Nepal. Kathmandu Univ Med J. Online First.

\begin{abstract}
Background

Ingested foreign body impaction on upper gastrointestinal tract is common incidence among children, older age group, mentally challenged individuals, and people the influence of alcohol. In most cases, the foreign bodies pass spontaneously and uneventfully but when this does not occur; endoscopic management to ensure removal under direct visualization is required. Relief upon removal of foreign body and prevention of complications is essential.
\end{abstract}

\section{Objective}

To assess the endoscopic management and outcome of foreign body impacted in the upper gastrointestinal tract.

\section{Method}

This is a hospital based observational retrospective cross sectional study involving 165 patients at Endoscopy Department of Dhulikhel Hospital in Nepal between November 2015 and October 2019. The data regarding the demographic profile, clinical characteristics and endoscopic findings were retrieved and analyzed to determine endoscopic interventions performed, complications and outcomes.

\section{Result}

One hundred and sixty five patients presenting with history of ingestion of foreign body were included in the study. The mean age of the patients was $46.8 \pm 19.1$ years with male predominance $(60 \%)$. The most common site of foreign body impaction was oesophagus (70\%). The most common foreign body encountered was bone (62.2\%) among which chicken bones (91.1\%) were most frequent. For the retrieval of sharp-pointed foreign bodies, rat forceps and graspers (45.7\%) were most commonly used. Total 14 cases required rigid oesophagoscopy as the foreign body could not be retrieved by flexible endoscopy.

\section{Conclusion}

Foreign body ingestion and its impaction in the upper gastrointestinal tract has been found to be common in endoscopic practise. Early detection and timely removal of foreign bodies is of utmost importance to avoid discomfort to the patient as well as to ensure successful removal without complications.

\section{KEY WORDS}

Endoscopy, Foreign body, Upper gastrointestinal tract 


\section{INTRODUCTION}

Foreign body ingestion, including food bolus and nonfood bolus, and their impaction on upper gastrointestinal tract (UGT) is a common incidence among children, older age group, mentally challenged individuals, and people under the influence of alcohol. ${ }^{1}$ Most commonly impacted foreign bodies include chicken bones, fish bones, coins, erasers to name a few. ${ }^{2}$ Sites common for impaction are cricopharyngeal sphincter, hypopharynx, esophagus, stomach, and duodenum. ${ }^{3}$ In most cases, the foreign bodies pass spontaneously and uneventfully through the digestive tract especially when they pass down through the esophagus. ${ }^{4}$ In about $20 \%$ of cases, however, the ingestion of foreign bodies is associated with a high risk of complications because of their size or shape or the host's medical status, thereby requiring endoscopic removal and in about 1-2\% surgery is required. ${ }^{5,6}$ When foreign bodies do not pass spontaneously, the discomforting alternative leads to symptoms of foreign body sensation, dysphagia, gagging, chest pain. These should be managed endoscopically to ensure removal under direct visualization, relief upon removal, and prevention of complications. When complicated, foreign body impaction results in perforation, hemorrhage, mediastinitis and retropharyngeal abscess. ${ }^{7}$ The complications are often related to the ingested object, location, and duration of time that passes until treatment. ${ }^{8}$

Endoscopic interventions are commonly performed procedure. However there are limited publications in the related discipline in Nepalese context. Hence this study aims to determine the demography, management approach and outcome of oesophageal foreign body cases that presented to a tertiary care centre.

\section{METHODS}

It was designed as a retrospective consecutive case series of all those patients who received endoscopic management of foreign bodies in the UGI tract, reflecting the experience of a single academic centre.

Sample size was calculated using $10 \%$ population prevalence and considering $80 \%$ power and $5 \%$ alpha error. Prior permission was taken from the institutional review board (IRB) - Dhulikhel Hospital (Reference no. 268/19) and prior to endoscopic procedure from every patient. The study group comprised 165 patients presenting in emergency or outpatient department with history of foreign body ingestion and food impaction, between November 2015 and October 2019. The demographic and clinical data were retrieved. Patients who did not undergo therapeutic intervention or patients who had incomplete medical records were excluded.

All the patients with foreign body ingestions and food impactions underwent urgent (with $24 \mathrm{hrs}$ ) endoscopic interventions either under local pharyngeal anesthesia or intravenous anesthesia. The patients underwent rigid esophagoscopy when indicated. Various endoscopic devices, including biopsy forceps, graspers, retrieval baskets and polypectomy snares were used to remove the ingested foreign bodies, depending on their nature and location.

The data regarding the demographic profile (age, sex and ethnicity), clinical characteristics (history and physical examination), endoscopic interventions (endoscopic techniques used, cases requiring rigid esophagoscopy, cases requiring open surgery) were retrieved and documented into the electronic files. Similarly endoscopic findings (type, nature and location of foreign body), underlying esophageal disease, missing dentures and operation details (sedation used, complications related to the procedure, underlying ulcer induced by foreign body) were also recorded for analysis.

For all statistical analyses, the Statistical Package for Social Sciences (SPSS) version 20.0 statistical software package (SPSS Inc, Chicago, IL, USA) was used.

\section{RESULTS}

A total of 165 patients with a mean age of $46.8 \pm 19.1$ years, were included in this study. The age ranged from 5 years to 86 years. Patients under the age of 16 years were categorized as children; there were total of 12 children with ingestion of foreign body (7.2\%). Male patients had a higher number with a total of 99 (60\%). The patients either presented primarily to our centre or were referred from Emergency departments of different centres. All patients underwent urgent (within 24 hours) oesophagogastroduodenoscopy (EGD) following foreign body ingestion. The ethnic group that predominated in our study was Mongols ( $n=73,44.2 \%$ ) (table 1 ).

The most common site of impaction of foreign body was oesophagus $(70 \%)$ with decreasing order of frequency in upper oesophagus (51.2\%), mid oesophagus (14.8\%) and lower oesophagus (4\%). Other sites of impaction were pharynx $(25.8 \%)$, stomach $(2.4 \%)$, duodenum $(0.8 \%)$ (table $2)$. The major types of foreign bodies were bones $(n=79$, $62.2 \%$ ) followed by meat boluses ( $n=34 ; 26.8 \%$ ). Among the bones that were encountered, most of them were chicken bones (91.1\%) and most common meat bolus encountered were also chicken meat bolus (61.8\%). Other types of foreign bodies included dental prosthesis, coins, metallic wires, safety pin (table 3,4) (fig. 1).

Sedation was required in 65(39.4\%) patients. Propofol was the sedation of choice in all cases with additional agents such as midazolam, fentanyl used as and when required. Selection of methods for endoscopic method used depended on the type and the location of the foreign body. In the study, for the retrieval of sharp-pointed foreign bodies, rat forceps and graspers $(n=58,45.7 \%)$ were most 
Table 1. Demographic profile of study population

\begin{tabular}{|c|l|l|}
\hline Demographic profile & Frequency $\mathbf{n = 1 6 5}$ & Percentage \\
\hline AGE (years) & & \\
\hline$<=10$ & 15 & 3.6 \\
\hline $11-20$ & 12 & 9.1 \\
\hline $21-30$ & 25 & 7.3 \\
\hline $31-40$ & 29 & 15.2 \\
\hline $41-50$ & 39 & 17.6 \\
\hline $51-60$ & 39 & 23.6 \\
\hline$>60$ & & 23.6 \\
\hline SEX & 99 & \\
\hline Male & 66 & 60 \\
\hline Female & & 40 \\
\hline ETHNICITY & 73 & \\
\hline Mongol & 36 & 44.2 \\
\hline Brahmin & 25 & 21.8 \\
\hline Newar & 14 & 15.2 \\
\hline Chettri & 17 & 8.5 \\
\hline Others & & 10.3 \\
\hline
\end{tabular}

Table 2. Foreign body detection and its location

\begin{tabular}{|c|c|c|c|}
\hline \multicolumn{2}{|c|}{ Foreign body detection and site } & \multirow{2}{*}{$\begin{array}{l}\text { Frequency } \\
n=165 \\
127\end{array}$} & \multirow{2}{*}{$\begin{array}{l}\text { Percentage } \\
77\end{array}$} \\
\hline & Yes & & \\
\hline 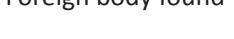 & No & 38 & 23 \\
\hline \multirow{6}{*}{$\begin{array}{l}\text { Site of foreign body } \\
\text { detection }(n=174)\end{array}$} & Pharynx & 34 & 26.8 \\
\hline & Upper Esophagus & 65 & 51.2 \\
\hline & Mid Esophagus & 19 & 14.8 \\
\hline & Lower Esophagus & 5 & 4 \\
\hline & Stomach & 3 & 2.4 \\
\hline & Duodenal Bulb & 1 & 0.8 \\
\hline
\end{tabular}

Table 3. Type of foreign body

\begin{tabular}{|c|c|c|}
\hline Type of foreign body & frequency & Percentage \\
\hline Bone & 79 & 62.2 \\
\hline Meat Bolus & 34 & 26.8 \\
\hline Dental Prosthesis & 6 & 4.7 \\
\hline Coins & 3 & 2.4 \\
\hline Metallic Wire & 3 & 2.4 \\
\hline Safety Pin & 1 & 0.8 \\
\hline Others & 1 & 0.8 \\
\hline
\end{tabular}

Table 4. Nature of impacted food bolus and bone

\begin{tabular}{|lllll|}
$\begin{array}{l}\text { Nature of impacted } \\
\text { food bolus and bone }\end{array}$ & Bone & Meat Bolus & Total & Percentage \\
\hline Chicken & 72 & 21 & 93 & 82.3 \\
\hline Mutton & 4 & 7 & 11 & 9.7 \\
\hline Buff & 0 & 6 & 6 & 5.3 \\
\hline Fish bone & 3 & 0 & 3 & 2.6 \\
\hline
\end{tabular}


Figure 1. A: Chicken bone lodged in mid esophagus, B: Meat Bolus impacted in the upper esophagus, C: Denture lodged in the mid-esophagus and D: after its removal with polypectomy snare, E: Coin lodged just below upper esophageal sphincter and F: after its removal with rat forceps

commonly used. Polypectomy snares was used in case of blunt objects including meat boluses and dentures $(n=15$, $11.8 \%$ ). The push technique (pushing the food bolus into the stomach) was used when food bolus or bone fragments could not be extracted out $(n=37,29.1)$ (table 5).

Table 5. Endoscopic technique used for management

\begin{tabular}{|lll|}
\hline Endoscopic technique used & $\begin{array}{l}\text { Frequency } \\
\text { (n=127) }\end{array}$ & Percentage \\
\hline Push into the stomach & 37 & 29.1 \\
\hline Pull with retrieval forceps & 58 & 45.7 \\
\hline Pull with Polypectomy snare & 15 & 11.8 \\
\hline Pull with Rigid Esophagoscopy & 14 & 11 \\
\hline Foreign Body in Stomach & 3 & 2.4 \\
\hline
\end{tabular}

Total 14 cases required rigid oesophagoscopy as the foreign body could not be retrieved by flexible endoscopy. All cases of rigid endoscopy were done in operation theatre under general anaesthesia after intubation. Most common foreign body retrieved in rigid oesophagoscopy was chicken bone $(n=8,57.14 \%)$ followed by artificial dentures $(n=3,21.43)$, mutton bone ( $n=2,14.29)$, meat bolus ( $n=1,7.14 \%)$.

There were no dislodgement of teeth, no perforation, no instances of mediastinitis, secondary to insertion of scope or removal of foreign body. However $26.7 \%$ patients had either erosion or ulcer induced by the foreign body or during removal which were managed conservatively. There were 3 cases of known oesophageal carcinoma of distal 
oesophagus producing obstruction of the foreign body proximal to the growth, 2 cases of suspected achalasia cardia and 2 cases had history of subnormal mental status.

\section{DISCUSSION}

Foreign body ingestion is a common problem and it can occur in any age group. In this study, children constituted $7.2 \%$ of total study population. Among adults, people above 50 constituted the major bulk (47.2\%) (table 1). A study from Manipal Teaching Hospital, Pokhara, Nepal by Koirala et al. showed that, $44.4 \%$ patients were children and $55.5 \%$ were adults. ${ }^{9}$ The findings by Adhikari et al. from Tribhuwan University Teaching Hospital, Kathmandu, Nepal was that foreign bodies were seen in $48.5 \%$ children and $51.5 \%$ adults. ${ }^{10}$ While the study from Kathmandu Medical College by Shrestha et al. found that foreign body impaction was more common in adult population with the most common age group being the fifth decade of life. ${ }^{11}$ In this study, $47.2 \%$ belonged to the age group above 50 . This is also consistent with study by Magalhães-Costa et al. which states that foreign body impaction is more common in the extremes of ages. ${ }^{12}$ So the age group of presentation is highly variable and both children and adults are at risks.

In this study, foreign bodies were found in 127 of 165 cases (77\%). This data is comparable with study published by Kim et al. where foreign body in oesophagus was reported to be $76.9 \% .{ }^{13}$ Similarly, Velitchkov et al. published a retrospective study of 542 cases and concluded that foreign body ingestion is a common entity. ${ }^{14}$ The results have contrasted with the studies published by Mosca et al. and Ciriza et al. where endoscopy revealed lower incidence of foreign bodies that is $52 \%$ and $64.5 \%$ respectively. ${ }^{15,16}$ The nature of the foreign bodies, the size and type of foreign body; underlying oesophageal disorders such as malignancy, stenosis which prevents spontaneous passage of the foreign body; and the timing of the endoscopy and subsequent spontaneous passage with time might be the reasons for the inconsistency.

The most common site of impaction of foreign body was oesophagus (70\%) predominantly in upper oesophagus. This is consistent with studies published by Li et al. being $58.4 \%$ and Zhang et al. being $84.5 \%$ in the esophagus. ${ }^{17,18}$ The oesophagus has four physiologically narrow sites, namely, the upper oesophageal sphincter, level of the aortic arch, main stem bronchus, and lower oesophageal sphincter. This might explain the most common location of lodgement of foreign body in the physiologically narrow site of the oesophagus.

The major types of foreign bodies were bones $(n=79$, $62.2 \%$ ) and most of them were chicken bones (91.1\%) in the present study. This was different from the study in children in which metallic coin was most common foreign body retrieved, while consistent with other study in which food impaction was more common than foreign objects. ${ }^{19,20}$
In the study from the United States, meat, particularly beef chicken or hot dogs, were the most common food impaction. ${ }^{21}$ While in Asia and coastal countries, fish was the most common food to cause impaction and mucosal trauma. ${ }^{22}$ However, in this study we found chicken bone as the most frequent detection probably because of more consumption as it is readily available.

Although the first accepted endoscopic method used to treat oesophageal food bolus impaction is the push technique this was used only in $29.1 \% .{ }^{23,24}$ Retrieval with rat forceps and graspers ( $n=58,45.7 \%)$ was the most commonly used technique. Similarly, in a case series published of 139 cases by Katsinelos et al. pull with dormia basket, Roth net or polypectomy snare (45.3\%) was the most common method used. ${ }^{25}$ So the method of choice for removal of foreign bodies varies greatly despite the recommendations depending upon the nature and size of the object.

Although endoscopy was initially attempted under local anesthesia, intravenous anesthesia with propofol was required in 65 (39.4\%) patients. This is mostly due to discomfort experienced by the patient and the technical difficulty of the procedure. Fourteen cases had to undergo rigid oesophagoscopy in the operation theatre because of failure of flexible endoscopy to retrieve the foreign bodies. All the rigid oesophagoscopy cases had undergone the procedure within $24 \mathrm{hrs}$ to reduce the complications related to the procedure as recommended by the European Society of Gastrointestinal Endoscopy (ESGE). ${ }^{4}$ Foreign body impaction lasting more that 24 hours is associated with the increased incidence of complications such as perforation with or without mediastinitis, retropharyngeal abscess, and aortoesophageal fistula. ${ }^{26}$

Besides bones ( $n=9,64.3 \%$ ) which was the most common foreign body requiring rigid oesophagoscopy, artificial dentures were second most common foreign bodies retrieved $(n=3,21.4)$. This is probably because of technical challenge related with removal of artificial denture with flexible device. The endoscopic extraction of dentures carries a high risk of perforation. ${ }^{27}$ However all 3 cases of dental prosthesis were removed without complications.

There were no significant complication related with the procedure besides erosion or ulcer induced by the foreign body or during endoscopic removal which were managed conservatively. This is contrary to the studies which have shown complications rate as high as $7 \% .{ }^{28}$ This might be due to smaller volume of cases and difference in nature of foreign bodies. The complications related to foreign body removal in the UGI tract need further prospective studies with larger numbers of patients to be confirmed. Although there were 2 cases of suspected achalasia cardia during endoscopy that might have lead to the foreign body impaction at distal oesophagus which needed manometric confirmation but were not followed up. 


\section{CONCLUSION}

The present study has found that ingestion of foreign body is a common clinical problem. Endoscopy is a highly effective for both diagnosis and extraction of ingested foreign

\section{REFERENCES}

1. Lee CY, Kao BZ, Wu CS, Chen MY, Chien HY, Wu LW, et al. Retrospective analysis of endoscopic management of foreign bodies in the upper gastrointestinal tract of adults. J Chin Med Assoc. 2019;82(2):105-9.

2. Ambe P, Weber SA, Schauer M, Knoefel WT.Swallowed Foreign Bodies in Adults. Dtsch Arztebl Int. 2012;109(50):869-75.

3. Shivakumar AM, Naik AS, Prashanth KB, Hongal GF, Chaturvedy G. Foreign bodies in upper digestive tract. Indian J Otolaryngol Head Neck Surg. 2006;58(1):63-8.

4. Birk M, Bauerfeind P, Deprez PH, Häfner M, Hartmann D, Hassan C, et al. Removal of foreign bodies in the upper gastrointestinal tract in adults: European Society of Gastrointestinal Endoscopy (ESGE) Clinical Guideline. Endoscopy. 2016;48(5):489-96.

5. Eisen GM, Baron TH, Dominitz JA, Faigel DO, Goldstein JL, Johanson $\mathrm{JF}$, et al; Guideline for the management of ingested foreign bodies. Gastrointest Endosc. 2002;55(7):802-06.

6. Lee HJ, Kim HS, Jeon J, Park SH, Lim SU, Jun CH, et al. Endoscopic foreign body removal in the upper gastrointestinal tract: risk factors predicting conversion to surgery. Surg Endosc. 2016;30(1):106-13.

7. Shreshtha D, Sikka K, Singh CA, Thakar A. Foreign Body Esophagus: When Endoscopic Removal fails. Indian J Otolarngol Head Neck Surg. 2013;65(4):380-2.

8. Geng C, Li X, Luo R, Cai L, Lei X, Wang C. Endoscopic management of foreign bodies in the upper gastrointestinal tract: a retrospective study of 1294 cases. Scand J Gastroenterol. 2017;52(11):1286-91.

9. Koirala K, Rai S, Chhetri S, Shah R. Foreign Body in the EsophagusComparison Between Adult and Pediatric Population. Nepal Journal of Medical Sciences. 2012;1(1):42-4.

10. Adhikari P, Shrestha BL, Baskota DK, Sinha BK. Accidental Foreign Body Ingestion: Analysis of 163 Cases. Int. Arch. Otorhinolaryngol. 2007;11(3):267-70.

11. Shrestha D. Management of Esophageal Foreign Body Using Endoscopic Approach: an Experience from Kathmandu Medical College Teaching Hospital. Journal of Kathmandu Medical College. 2018;6(4):136-9.

12. Magalhães-Costa $P$, Carvalho $L$, Rodrigues JP, Túlio MA, Marques $\mathrm{S}$, Carmo J et al. Endoscopic Management of Foreign Bodies in the Upper Gastrointestinal Tract: An Evidence-Based Review Article. GE Port J Gastroenterol. 2015; 23(3):142-52.

13. Kim JK, Kim SS, Kim JI, Kim SW, Yang YS, Cho SH et al. Management of foreign bodies in the gastrointestinal tract: an analysis of 104 cases in children. Endoscopy. 1999;31(4):302-04.

14. Velitchkov NG, Grigorov GI, Losanoff JE, Kjossev KT. Ingested foreign bodies of the gastrointestinal tract: retrospective analysis of 542 cases. World J Surg. 1996;20(8):1001-05. bodies with relatively low complication. Early endoscopy is the key to therapeutic success as well as reducing the risk of complications.

15. Mosca S, Manes G, Martino R, Amitrano L, Bottino V, Bove A, et al. Endoscopic management of foreign bodies in the upper gastrointestinal tract: report on a series of 414 adult patients. Endoscopy. 2001;33(8):692-96.

16. Ciriza C, García L, Suárez P, et al. What predictive parameters best indicate the need for emergent gastrointestinal endoscopy after foreign body ingestion? J Clin Gastroenterol. 2000;31(1):23-8.

17. Li ZS, Sun ZX, Zou DW, Xu GM, Wu RP, Liao Z. Endoscopic management of foreign bodies in the upper-GI tract: experience with 1088 cases in China. Gastrointest Endosc. 2006;64(4):485-92.

18. Zhang S, Cui Y, Gong X, Gu F, Chen M, Zhong B. Endoscopic management of foreign bodies in the upper gastrointestinal tract in South China: a retrospective study of 561 cases. Dig Dis Sci. 2010;55(5):1305-12.

19. Shivakumar AM, Naik AS, Prashanth KB, Yogesh BS, Hongal GF. Foreign body in upper digestive tract. Indian J Pediatr. 2004;71(8):689-93.

20. Okan I, Akbaş A, Küpeli M, Yeniova AÖ, Esen M, Özsoy Z, et al. Management of foreign body ingestion and food impaction in adults: A cross-sectional study. Ulus Travma Acil Cerrahi Derg. 2019;25(2):159-166.

21. Longstreth GF, Longstreth KJ, Yao JF. Esophageal food impaction: epidemiology and therapy. A retrospective, observational study. Gastrointest Endosc. 2001;53(2):193-198.

22. Stack LB, Munter DW. Foreign bodies in the gastrointestinal tract. Emerg Med Clin North Am. 1996;14(3):493-521.

23. Weinstock LB, Shatz BA, Thyssen SE. Esophageal food bolus obstruction: evaluation of extraction and modified push techniques in 75 cases. Endoscopy. 1999;31(6):421-25.

24. Vicari JJ, Johanson JF, Frakes JT. Outcomes of acute esophageal food impaction: success of the push technique. Gastrointest Endosc. 2001;53(2):178-81.

25. Katsinelos P, Kountouras J, Paroutoglou G, Zavos C, Mimidis K, Chatzimavroudis G. Endoscopic techniques and management of foreign body ingestion and food bolus impaction in the upper gastrointestinal tract: a retrospective analysis of 139 cases. J Clin Gastroenterol. 2006;40(9):784-9.

26. Chaves DM, Ishioka S, Félix VN, Sakai P, Gama-Rodrigues JJ. Removal of a foreign body from the upper gastrointestinal tract with a flexible endoscope: a prospective study. Endoscopy. 2004;36(10):887-92.

27. Nwaorgu OG, Onakoya PA, Sogebi OA, Kokong DD, Dosumu OO. Esophageal impacted dentures. J Natl Med Assoc. 2004;96(10):135053.

28. Geraci G, Sciume' C, Di Carlo G, Picciurro A, Modica G. Retrospective analysis of management of ingested foreign bodies and food impactions in emergency endoscopic setting in adults. BMC Emerg Med. 2016;16(1):42. 